\title{
On the History of Marine Fisheries: Report of the Woods Hole Workshop
}

John H. Steele and Mary Schumacher

Woods Hole Ocenographic Institution - Woods Holc, Massachusetts USA

\section{$\mathbf{T}$}

he theme of the Woods Hole workshop, "On the History of Marine Fisheries," was selected in light of the results of an earlier meeting in Monterey (see synopsis by Bradley, this volume), where participants had proposed that a Census of Marine Life be pursued as an iterative process of modeling and observation. The Monterey proposal included a pilot observational phase that would concentrate on filling in large gaps in existing ecosystem models, particularly at the upper trophic levels. Building on these ideas, organizers of the Woods Hole workshop asked their participants to address two main questions:

-What do modeling and observational studies tell us about the state of marine fisheries prior to, and in the early stages of, exploitation?

- What further studies should be undertaken to improve the state of knowledge in this area?

The presentations and discussion covered a number of important issues raised by historical fisheries data, including scales of variability in fish populations, multispecies effects of fishing, and the ecosystem role of the intermediate trophic level. Perhaps the most important issue is the wide range of evidence supporting an estimate of roughly an order-of-magnitude reduction in fish biomass in Northwest Atlantic fisheries, relative to pre-exploitation or early exploitation levels, and signs of similar trends in other intensively exploited fisheries. Many instances of such evidence were cited, such as qualitative accounts in the popular literature of 300 years ago, more formal historical accounts and early fisheries records documenting enormous catches with fairly unsophisticated techniques, contemporary reports of catch rates in newly developing fisheries, and traditional stock assessments based on scientific surveys, which indicate that, without any increase in reproduction rates, fish abundance levels could be increased by a factor of 5 , often 10 , and some-

times 20 simply by leaving the existing stocks unexploited.

Much of the discussion was devoted to the implications of this estimated decline in fish biomass for the structure of "pristine" ecosystems, relative to existing ecosystem models. Such models depict present systems at a steady-state and use either biomass fluxes or energy flow rates as the state variable to be conserved or balanced. Given the balancing requirement, the estimated reduction in biomass at the upper trophic levels suggests either that primary production must once have been much higher, or that energy flows across trophic levels have changed considerably.

The first scenario raises the possibility that environmental changes, rather than overfishing, may be responsible for the estimated declines in biomass. Although this is inconsistent with our understanding of some of the best-known cases of intensively exploited fisheries, some historical fisheries records do indicate that environmental change can drive steep stock declines. For example, the record of sardine scales in sedimentary deposits in the California Current provides support for such an interpretation, at least with

The first scenario raises the possibility that environmental changes, rather than overfishing,

may be responsible for the estimated declines in biomass. respect to small, short-lived pelagic fish. The record dates back to about $400 \mathrm{AD}$ and thus spans major climatedriven contractions of sardine habitat as well as periods of intensive exploitation. It shows that sardines are extremely sensitive both to over-
vironmental change, and that roughly fishing and to environmental change, and that roughly
100 -fold declines in abundance are possible even without fishing.

It is important to recognize that such historical data might represent only local variability in abundance, because sediment cores are taken at only a few discrete sites. In the context of a Census of Marine Life, this issue is important for our view of the spatial and temporal variability of unexploited populations and, therefore, of the sampling requirements for estimating their dynamics. 
Another striking feature of the recent historical data are the loosely coupled, inverse shifts in abundances of different species, such as the well-known sardineanchovy switches around the Pacific. This and other examples that are limited to pelagic species can be considered to be relatively explicable consequences of shifts in competitive advantage. More interesting but less explicable are switches in abundance between pelagic and demersal stocks, which have occurred in the last few decades and can be attributed largely, if not entirely, to overfishing. Finally, there is circumstantial evidence of pelagic-demersal switches before fishing on the Scotian Shelf, the Grand Banks, and Georges Bank. This leads one to think that there have been major changes in the abundance of other fish stocks concomitant with the observed decline in demersal species.

The structure of fish stocks is not necessarily the only change that marine ecosystems have undergone. At present, gelatinous plankton are considered a dominant component of many shelf ecosystems, especially in their presumed role as principal consumers of "detritus." Energy-flow models suggest that pristine fish stocks needed significantly more energy input, which in turn implies that a major diversion of energy flow from vertebrate to gelatinous species may have taken place. Such speculations demand that studies of present or past unexploited systems consider not only the top trophic levels but also the intermediate trophic structure, about which we currently know very little.

These puzzles highlight the need for additional observational effort to fill important gaps in our models and ultimately to confirm or disprove them. Modeling is essential, since it really is not feasible to sample enough of the ocean that we could measure the abundance and distribution of marine life directly, and several modeling approaches will be needed. Basic ecological knowledge of marine food webs is critical, particularly an appreciation of the microbial loop and an elucidation of the undoubtedly important but poorly understood role of gelatinous organisms (see synopsis by Levi, Stone and Schubel, this volume). Energyflow models highlight the critical nature of the "detritus" terms in pristine vs. overfished systems, and can demonstrate how changes such as the pelagic-demersal switch can be accommodated. But such "bookkeeping" does not help us understand how the system can switch from one state to another - from pristine to exploited, pelagic to demersal, large to small reservoirs of detritus.

If we require models that can "predict" past systems or indicate strategies to observe open-ocean populations, then we need dynamic models. At present, such models would be difficult, if not impossible, to validate. The consensus is that they help define problems, not supply answers, and thus leave unresolved the question of exactly what form the field study component of a Census of Marine Life should take.

With its focus on "pristine" eocsystems, this workshop highlighted a number of puzzles concerning the nature and mechanisms of ecosystem change and underlying gaps in the observational record and current modeling approaches. Alternative models of pristine systems and the implications for the top-down effect of intensive fishing are summarized in Steele and Schumacher (1999).

\section{REFERENCES}

Steele, J.H. and M. Schumacher, 1999: Ecosystem structure before fishing. Fisheries Research, in press.

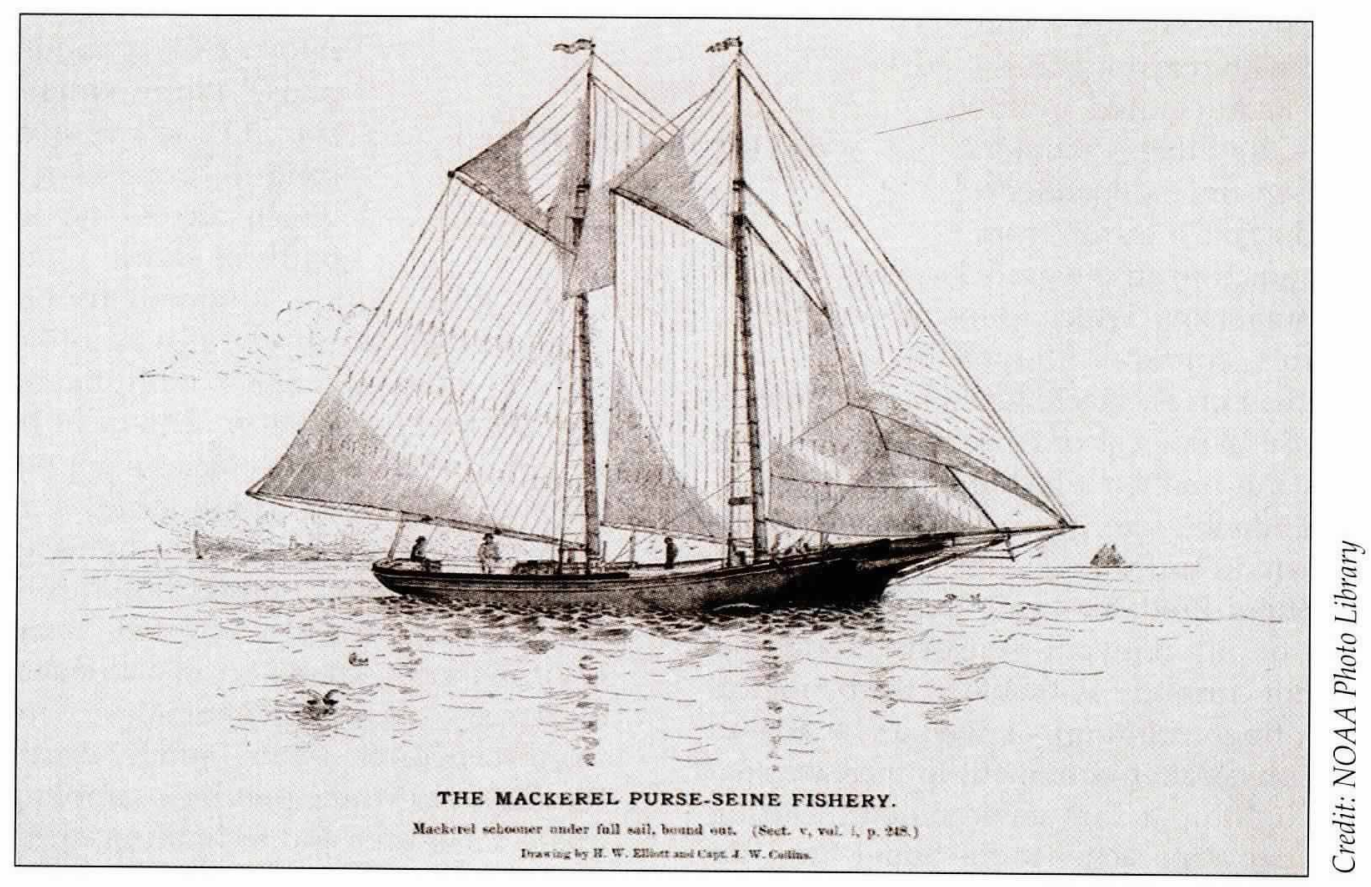

